\title{
Resting Energy Expenditure of Master Athletes: Accuracy of Predictive Equations and Primary Determinants
}

\begin{abstract}
Petra Frings-Meuthen ${ }^{1 *}$, Sara Henkel ${ }^{1}$, Michael Boschmann ${ }^{2}$, Philip D. Chilibeck ${ }^{3}$, José Ramón Alvero Cruz', Fabian Hoffmann ${ }^{1,5}$, Stefan Möstl', Uwe Mittag ${ }^{1}$, Edwin Mulder ${ }^{1}$, Natia Rittweger ${ }^{1}$, Wolfram Sies ${ }^{1}$, Hirofumi Tanaka ${ }^{6}$ and Jörn Rittweger ${ }^{1,7}$

${ }^{1}$ German Aerospace Center (DLR), Institute of Aerospace Medicine, Cologne, Germany, ${ }^{2}$ Experimental and Clinical Research Center - a joint co-operation between Charité Universitätsmedizin Berlin and Max Delbrück Center for Molecular Medicine, Berlin, Germany, ${ }^{3}$ College of Kinesiology, University of Saskatchewan, Saskatoon, SK, Canada, ${ }^{4}$ Facultad de Medicina, Instituto de Investigación Biomédica de Málaga, Universidad de Málaga, Málaga, Spain, ${ }^{5}$ Department of Internal Medicine III, University Hospital Cologne, Cologne, Germany, ${ }^{6}$ Department of Kinesiology and Health Education, The University of Texas at Austin, Austin, TX, United States, ${ }^{7}$ Department of Pediatrics and Adolsecent Medicine, Hospital Cologne, Cologne, Germany
\end{abstract}

Resting energy expenditure (REE) is determined mainly by fat-free mass (FFM). FFM depends also on daily physical activity. REE normally decreases with increased age due to decreases in FFM and physical activity. Measuring REE is essential for estimating total energy expenditure. As such, there are a number of different equations in use to predict REE. In recent years, an increasing number of older adults continue to participate in competitive sports creating the surge of master athletes. It is currently unclear if these equations developed primarily for the general population are also valid for highly active, older master athletes. Therefore, we tested the validity of six commonly-used equations for predicting REE in master athletes. In conjunction with the World Masters Athletic Championship in Malaga, Spain, we measured REE in 113 master athletes by indirect calorimetry. The most commonly used equations to predict REE [Harris \& Benedict (H\&B), World Health Organization (WHO), Müller (MÜL), Müller-FFM (MÜLFFM), Cunningham (CUN), and De Lorenzo (LOR)] were tested for their accuracies. The influences of age, sex, height, body weight, FFM, training hours per week, phase angle, ambient temperature, and athletic specialization on REE were determined. All estimated REEs for the general population differed significantly from the measured ones $(H \& B$, WHO, MÜL, MÜL-FFM, CUN, all $p<0.005)$. The equation put forward by De Lorenzo provided the most accurate prediction of REE for master athletes, closely followed by FFM-based Cunningham's equation. The accuracy of the remaining commonly-used prediction equations to estimate REE in master athletes are less accurate. Body weight $(p<0.001)$, FFM $(p<0.001)$, FM $(p=0.007)$, sex $(p=0.045)$ and interestingly temperature $(p=0.004)$ are the significant predictors of REE. We conclude that REE in master athletes is primarily determined by body composition and ambient temperature. Our study provides a first estimate of energy requirements for master athletes in order to cover adequately athletes' energy and nutrient requirements to maintain their health status and physical performance.

Keywords: resting energy expenditure, master athletes, energy metabolism, predictive equation, body composition 


\section{INTRODUCTION}

Master athletes are individuals older than 35 years who continue physical training and take part in athletic competitions, often throughout their entire life, which can be regarded as a model of active aging (Tanaka et al., 2019). Over the past decades, the number of master athletes has increased steadily (Figure 1). Because of their strenuous training routine and specific demands that age-related physiological changes place, master athletes have distinct nutritional requirements (Desbrow et al., 2019). A sufficient energy intake is mandatory to maintain overall health and competitive performance of these aging athletes (Schofield et al., 2019). Resting energy expenditure (REE), the fraction of energy at rest to maintain essential body functions, contributes $60-70 \%$ to total daily energy expenditure (TEE). REE is determined by fat-free mass (FFM) (Sullo et al., 2004; Schofield et al., 2019). FFM accounts for $60-70 \%$ of the total REE, and fat mass (FM) for only 5-7\% of REE (Johnstone et al., 2005). REE declines with increasing age, which is thought to be primarily driven by the gradual decline in FFM due to a loss of muscle mass (Tzankoff and Norris, 1977; Welle and Nair, 1990). Additionally, albeit to a lesser extent, reduced physical activity contributes to this decline in REE (Poehlman et al., 1991a,b,c; Vaughan et al., 1991). Master athletes can theoretically counteract such age-related decreases in FFM and thereby in REE, provided that energy intake levels are sufficient. Having valid and reliable REE values is crucial to establish achievable goals for dietary and exercise interventions involving master athletes (Amaro-Gahete et al., 2019). Indirect calorimetry (IC) has been established as a noninvasive method for measuring REE with good precision and accuracy (Haugen et al., 2007; Pinheiro Volp et al., 2011; Delsoglio et al., 2019). IC is based on measuring oxygen $\left(\mathrm{O}_{2}\right)$ consumption and carbon dioxide (CO2) dissipation, which is coupled to the metabolism of energy-rich substrates such as carbohydrates and fats. Total average daily REE in kcal was calculated using the modified Weir equation (Weir, 1949) as follows:

$$
\begin{aligned}
\operatorname{REE}(\mathrm{kcal} / \text { day })= & {\left[\left(\mathrm{VO}_{2} \times 3.941\right)+\left(\mathrm{VCO}_{2} \times 1.11\right)\right.} \\
& \left.+\left(\mathrm{uN}_{2} \times 2.17\right)\right] \times 1,440
\end{aligned}
$$

The urinary nitrogen component $\left(\mathrm{uN}_{2}\right)$ is often excluded when calculating EE because it only accounts for around $4 \%$ of the true energy expenditure. It contributes only to a small error of $1-2 \%$ in the calculation of final REE in both inpatients and outpatients. Thus, the abbreviated equation below is commonly used (Ferrannini, 1988).

$\operatorname{REE}(\mathrm{kcal} /$ day $)=\left[\left(\mathrm{VO}_{2} \times 3.941\right)+\left(\mathrm{VCO}_{2} \times 1.11\right)\right] \times 1,440$.

However, the IC technique is time-consuming, expensive, and, unavailable in daily practice. Accordingly, REE as well as TEE are often predicted via one of various prediction equations (Vander Weg et al., 2004; ten Haaf and Weijs, 2014; Cherian et al., 2018; Amaro-Gahete et al., 2019; Schofield et al., 2019). The Harris \& Benedict (H\&B), World Health Organization (WHO), Müller (MÜL), Müller-FFM (MÜL-FFM) and Cunningham (CUN) equations are most commonly used, but none of these standard prediction equations fits for every individual. While H\&B, WHO, MÜL only take age, sex, body weight and/or height into account, the equations by Müller-FFM and Cunningham also use FFM as a contributing factor (Harris and Benedict, 1918; Cunningham, 1980; WHO, 1985; De Lorenzo et al., 1999; Müller et al., 2004). Given that all predictive equations include age as covariate and that the underlying study cohorts likely only involved relatively sedentary older adults, it remains unclear whether these predictive equations would be accurate for highly active, older master athletes. To further highlight this concern, the accuracy of REE equations has already been questioned for athletic populations in general (Thompson and Manore, 1996;

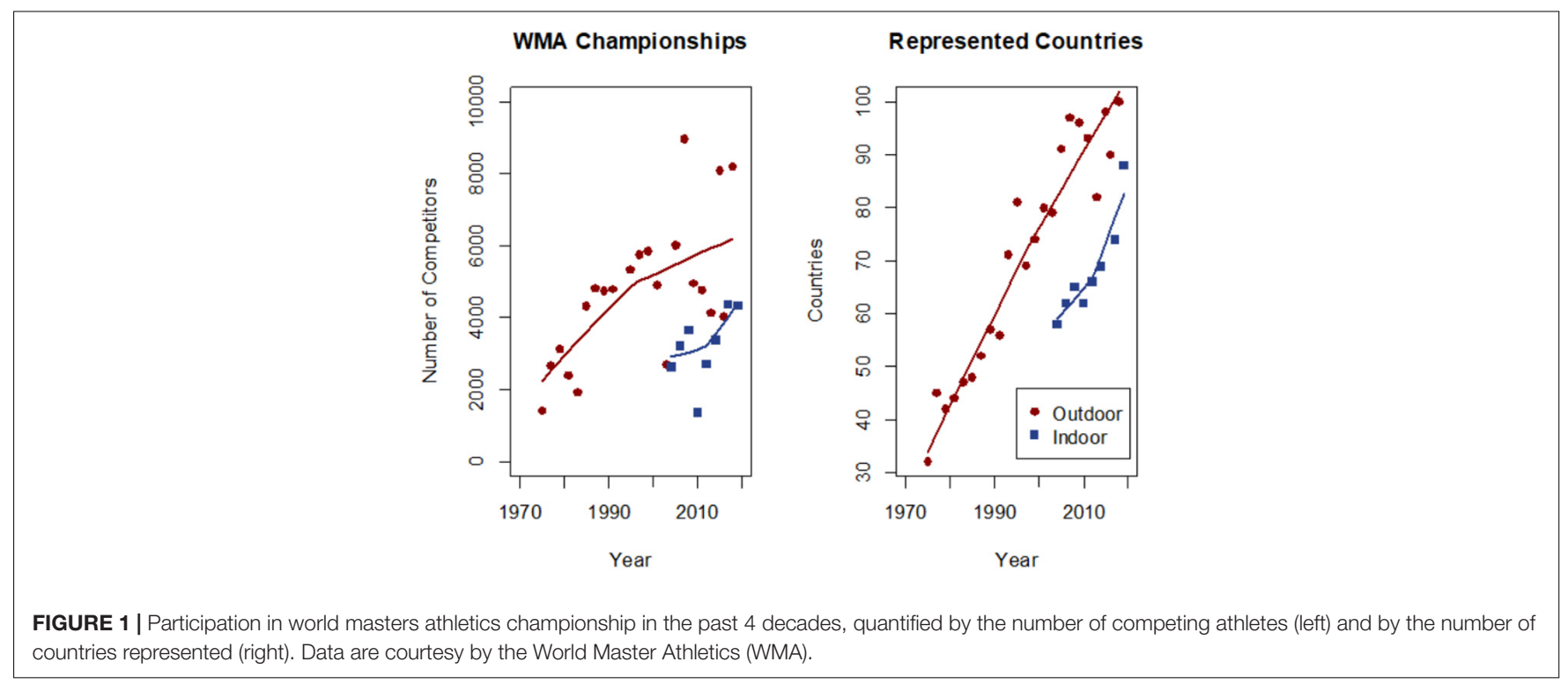


De Lorenzo et al., 1999; ten Haaf and Weijs, 2014; Jagim et al., 2018; Schofield et al., 2019) because data concerning subjects' physical activity involved in the development of the various equations were not considered. Studies on young athletes show increased energy requirements, but also emphasize substantial individual differences depending on the type of exercise activity (Frączek et al., 2019). The most widely-used equation for athletes comes from De Lorenzo (De Lorenzo et al., 1999). These authors studied seven published REE equations for estimating REE in young male athletes, aiming to create a specific equation for male athletes. Currently, the American College of Sports Medicine (ACSM) recommends the prediction equations developed by Cunningham and, interestingly, also the one by Harris \& Benedict for estimating REE in athletes (Rodriguez et al., 2009), although these equations have not been developed for the athletic population. More importantly, the accuracy of REE prediction models has not been validated specifically for these populations, and certainly not for master athletes. The number of studies measuring REE in older athletes is small. Available studies suggest that older men who are competitively physically active have a higher REE compared with age-matched sedentary individuals (Poehlman and Horton, 1990; Campbell et al., 1994). This is confirmed by a later study (Ryan et al., 1996; Van Pelt et al., 1997) that REE was greater in both young and older female athletes than in sedentary controls of the same age. A significant increase in REE was also observed in older female athletes after a short training phase of only 6 weeks (Stavres et al., 2019).

Thompson \& Manore (Thompson and Manore, 1996) reported that traditionally-used equations for estimating metabolic rates do not apply well to about $50 \%$ of athletes and that the Cunningham equation provides an accurate estimate of REE when determining energy needs of highly active people. Equations taking FFM into account seem to be the most reasonable approach to predict REE in athletes (ten Haaf and Weijs, 2014). However, De Lorenzo failed to determine FFM as the best predictor of REE for male athletes, instead the combination of height and body mass were the best predictors (De Lorenzo et al., 1999).

With this information as background, the purpose of this study was to test the accuracy of six common equations for predicting REE in master athletes and to address which other anthropometric and environmental characteristics influence REE in this specific cohort. We hypothesized that most of the existing equations would underestimate REE because of the higher FFM proportion in master athletes vs. sedentary adults.

\section{MATERIALS AND METHODS}

\section{Study Setting and Subjects}

The Masters Athletic Field Study 2018 (MAFS-18) aimed to assess physiological and mental constituents of physical fitness and well-being in master athletes. The present investigation is a sub-study of the MAFS-18, which was implemented during the 23rd World Masters Athletics Championship in September 2018 in Malagà, Spain. Any who was admitted to the championship as a competing athlete was allowed to participate. Exclusion criteria were injuries or illnesses that affected jump tests or contraction of the calf muscle, another main outcome measure of the MAFS-18. Criteria for early termination of the study were pathological findings during measurements or voluntary termination by participants. Athletes were made aware of the study in advance by direct e-mails and posters. The study protocol was approved by the ethical committee of the North Rhine Medical Association (Ärztekammer Nordrhein lfd Nr. 2018171), and the study had been registered on the German register for clinical trials ${ }^{1}$ with registration number DRKS00015172. All the participants signed informed consent to participate in the present study.

A hundred and thirteen athletes (79 men, 34 women), 35-84 years old, were studied. Athletes were asked to fast overnight, at least $12 \mathrm{~h}$, before the test session. They were requested to minimize high intensity physical activity or competitions $24 \mathrm{~h}$ before testing.

\section{Experimental Design}

The MAFS-18 study is a field study in an analytical cross-sectional design, performed once under field conditions. The study flow involved to first sign in at the registration office, the collection of anthropometric and training data, and body composition. Then, an appointment was made for a subsequent day to take REE-measurements.

\section{Measurements}

All the measurements were conducted in the morning between 7.00 and $11.00 \mathrm{am}$ in a dedicated room of the main stadium close to the registration office (room temperature $27.6 \pm 1.9^{\circ} \mathrm{C}$, ambient pressure $765 \mathrm{mmHg}$, ambient humidity 60\%).

\section{Anthropometric Measurements}

A stadiometer was used for assessing height to the nearest of $0.1 \mathrm{~cm}$, body weight was measured by a calibrated balance scale with an accuracy of $100 \mathrm{~g}$, both measured standing.

\section{Body Composition}

Body composition was measured by a segmental multi-frequency bioelectrical impedance analyzer (BIA) (InBody S10, Eschborn, Germany), following manufacturer's instructions. The electrodes were attached to the participant in supine position on the right hand and right foot with legs apart. Resistance and reactance were determined using an electric alternating current of $800 \mathrm{~mA}$ and multiple frequencies of 5, 50, and $250 \mathrm{kHz}$. Body composition indicators including skeletal muscle mass (SMM), soft lean mass (SLM), percentage of body fat (PBF), fat free mass (FFM), fat mass (FM), intracellular water (ICW), extracellular water (ECW), total body water (TBW), mineral content and protein content were measured. Phase angle at $50 \mathrm{kHz}$ was calculated by using the equation: phase angle $\left({ }^{\circ}\right)=\arctan$ (reactance/resistance) $\mathrm{x}(180 / \pi)$.

\footnotetext{
${ }^{1}$ www.drks.de
} 


\section{Indirect Calorimetry}

Resting energy expenditure was measured by indirect calorimetry using a canopy device (Quark RMR, COSMED Deutschland $\mathrm{GmbH}$, Fridolfing, Germany), following manufacturer's instructions and settings. After gas- and flowmeter-calibration, a two-minute REE test-measurement was conducted, before the main measurement over 30 min started. Oxygen consumption $\left(\mathrm{VO}_{2}, \mathrm{ml} / \mathrm{min}\right)$ and carbon dioxide production $\left(\mathrm{VCO}_{2}, \mathrm{ml} / \mathrm{min}\right)$ were measured for calculating REE. Indirect calorimetry was performed in the morning between 7.00 and 11.00 a.m. after an overnight fast in a separate corner of the examination room with an ambient temperature of $27.6 \pm 1.9^{\circ} \mathrm{C}$. The minimum duration of measurement was $30 \mathrm{~min}$ and the first $5 \mathrm{~min}$ were discarded. During measurements, subjects had to remain motionless, were not allowed to speak, or fall asleep. A protocol was taken whether they moved or felt asleep. Corresponding data points were excluded from the analysis. The device collected a measured value every $10 \mathrm{~s}$ for 30. The flow rate under the hood was adjusted so that the expiratory air $(\mathrm{FeCO} 2)$ was between $0.9-1.0 \mathrm{l}$ and the urinary nitrogen value was set to $8.00064 \mathrm{~g} /$ day. Data were collected every $10 \mathrm{~s}$ for $30 \mathrm{~min}$. The experimental conditions were standardized for each subject by means of a checklist. The CVs for the repeated REE-measurements were $13 \%$ in and $14 \%$ in women.

\section{Data Processing}

The first $5 \mathrm{~min}$ and some outliers of the indirect calorimetry data collection were removed and average values of $\mathrm{VO}_{2}$ and $\mathrm{VCO}_{2}$ were taken to calculate REE and respiratory exchange ratio (RER) as previously described (Ferrannini, 1988).

Directly-measured REE values were compared with a variety of REE values predicted based on anthropometric data. Equations of Harris \& Benedict (H\&B) (Harris and Benedict, 1918), WHO (WHO, 1985), Müller et al. (MÜL) (Müller et al., 2004), Müller-FFM (MÜL-FFM) (Müller et al., 2004), Cunningham (CUN) (Cunningham, 1980), and De Lorenzo et al. (LOR) (De Lorenzo et al., 1999) were used for comparison.

Harris \& Benedict defined REE as an individual's heat production assessed $12-14 \mathrm{~h}$ after the last meal at rest (Harris and Benedict, 1918). The underlying cohort consisted of 333 subjects, and height, age, body weight, and sex were reported as strongest predictors of REE:

$$
\begin{aligned}
\text { Men: } & \text { REE }(\mathrm{kcal} / \mathrm{d})=66.47+13.75 \times \text { Bodyweight }(\mathrm{kg}) \\
& +5.0 \times \text { Height }(\mathrm{cm})-6.76 \times \text { Age }(\text { years }) . \\
\text { Women }: & \operatorname{REE}(\mathrm{kcal} / \mathrm{d})=655.1+9.56 \times \text { Bodyweight }(\mathrm{kg}) \\
& +1.85 \times \operatorname{Height}(\mathrm{cm})-4.68 \times \text { Age }(\text { years }) .
\end{aligned}
$$

World Health Organization equation were calculated using several studies aimed at estimating the food requirements of certain populations by measuring REE and physical activity (WHO, 1985). A total of 7,549 subjects were measured and additional mean REEs of 3,874 other study measurements were included to define prediction equations including sex, body weight and age as greatest influencing factors:

$$
\begin{aligned}
\text { Men } 30-60 \text { years }: \text { REE }(\mathrm{kcal} / \mathrm{d})= & 11.6 \times \text { Bodyweight }(\mathrm{kg}) \\
& +879 . \\
\text { Men }>60 \text { years }: \operatorname{REE}(\mathrm{kcal} / \mathrm{d})= & 13.5 \times \text { Bodyweight }(\mathrm{kg}) \\
& +487 . \\
\text { Women } 30-60 \text { years }: \operatorname{REE}(\mathrm{kcal} / \mathrm{d})= & 8.7 \times \text { Bodyweight }(\mathrm{kg}) \\
& +829 . \\
\text { Women }>60 \text { years }: \operatorname{REE}(\mathrm{kcal} / \mathrm{d})= & 10.5 \times \text { Bodyweight }(\mathrm{kg}) \\
& +596 .
\end{aligned}
$$

Müller et al. (2004) compared equations of WHO with new data of a compiled German database, where REE measurements were conducted on 2,528 German participants to specify the WHO equations for the German population. He defined two different equations, one containing body composition data including fat free mass (FFM) and fat mass (FM):

$$
\begin{aligned}
\operatorname{REE}(\mathrm{kcal} / \mathrm{d})= & {[0.047 \times \text { Bodyweight }(\mathrm{kg})+1.009} \\
& \times \operatorname{sex}(0=\text { female }, 1=\text { male })-0.01452 \\
& \times \text { age }(\text { years })+3.31] \times 1,000 / 4.184 \\
\operatorname{REE}(\mathrm{kcal} / \mathrm{d})= & {[0.05192 \times F F M(\mathrm{~kg})+0.04036 \times F M(\mathrm{~kg})} \\
& +0.869 \times \operatorname{sex}(0=\text { female }, 1=\text { male })-0.01181 \\
& \times \text { age }(\text { years })+2.992] \times 1,000 / 4.184
\end{aligned}
$$

Cunningham solidified Harris \& Benedict's idea that FFM could be the greatest influencing factor on REE and developed an equation with FFM as the only parameter with participants from the Harris \& Benedict's study (Cunningham, 1980):

$$
R E E(\mathrm{kcal} / \mathrm{d})=500+22 \times F F M(\mathrm{~kg}) .
$$

De Lorenzo et al. (1999) defined an equation specifically for athletes. REE of 51 young (age $23.3 \pm 3.5$ years) male subjects, who exercised regularly at least $3 \mathrm{~h}$ per day was measured and the following equation was derived:

$$
R E E=-857+9 \times \operatorname{Bodyweight}(\mathrm{kg})+11 \times \operatorname{Height}(\mathrm{cm}) .
$$

\section{Statistical Analyses}

Data were collected with Research Electronic Data Capture with (REDCap ${ }^{\circledR}$ ). Statistical Package for Social Sciences (SPSS Version 26, IBM) was used for all statistical analyses. At first, all parameters were tested for normality by Shapiro-WilkTest. Non-parametric Mann-Whitney-U-Test was selected for comparison of estimated and measured REE. Bland-Altman analysis was selected to assess differences between measured and predicted REE. The differences between the measured and predicted values were set against their mean values, and the limits of agreement were defined. A twofold standard deviation is accepted as the tolerance limit, as it should 
cover $95 \%$ of all data. Linear regression analysis was used to evaluate the REE-FFM association. Multiple-regression analysis was used to evaluate independent relationships between REE and sex, age, height, body weight, FFM, training hours per week, phase angle, and athletic specialization. Sex and sport speciality (endurance, power, or mixed) represent categorical variables, which first needed to be encoded. Female sex and power as sports were chosen as reference categories, which allows a quantitative comparison of all categories with the reference categories. Significance level for all tests was set at 0.05. Subjects characteristics and environmental data are expressed as mean $\pm \mathrm{SD}$, all other results as mean \pm SEM.

\section{RESULTS}

Subject characteristics' are presented in Table $\mathbf{1 .}$

\section{Comparison of Measured REE and Predicted REE}

As illustrated in Figure 2, predicted REEs (REEp) using equations created for the general population differed significantly from the directly-measured REE ( $\left.\mathrm{REE}_{\mathrm{m}}\right)(p<0.001$ for $\mathrm{H} \& \mathrm{~B} ; p=0.001$ for WHO; $p=0.004$ for MÜL; $p=0.004$ for MÜL-FFM; $p=0.003$ for CUN). More specifically, the equations H\&B, WHO, MÜL, and MÜL-FFM underestimated, and CUN overestimated REE in both sexes. Predicted REE by LOR was not significantly different from the measured $\operatorname{REE}(p=0.750)$.

For male athletes, mean differences between measured and predicted REE were smallest for LOR with $15.3 \pm 17.7 \mathrm{kcal} / \mathrm{d}$ ( $1 \%$ deviation from the measured REE) followed by CUN with $-76.8 \pm 18.4 \mathrm{kcal} / \mathrm{d}(-4 \%$ deviation), MÜL with $81.7 \pm 18.0 \mathrm{kcal} / \mathrm{d}$ (5\% deviation), MÜL-FFM with $110.6 \pm 17.7 \mathrm{kcal} / \mathrm{d}$ (7\% deviation) and WHO with $113.6 \pm 19.9 \mathrm{kcal} / \mathrm{d}$ ( $8 \%$ deviation). The mean difference is highest for $\mathrm{H} \& \mathrm{~B}$ with $174.56 \pm 18.56 \mathrm{kcal} / \mathrm{d}$ (12\% deviation).

For women, mean differences between measured and predicted RER were also smallest for LOR with $-62.0 \pm 26.7 \mathrm{kcal} / \mathrm{d}(-4 \%$ deviation from the measured REE) followed by CUN with $-99.8 \pm 23.2 \mathrm{kcal} / \mathrm{d}(-6 \%$ deviation) and WHO with $128.9 \pm 28.1 \mathrm{kcal} / \mathrm{d}$ (10\% deviation). The mean difference is highest for MÜL with $156.1 \pm 7.0 \mathrm{kcal} / \mathrm{d}$

TABLE 1 | Subjects characteristics'.

\begin{tabular}{lcc}
\hline & \multicolumn{1}{c}{ Men } & Women \\
\hline Age (years) & $57.14 \pm 11.65(35-84)$ & $54.91 \pm 11.60(35-80)$ \\
Height $(\mathrm{cm})$ & $174.86 \pm 7.25(160.0-197.1)$ & $164.95 \pm 5.99(153.1-178.8)$ \\
Weight $(\mathrm{kg})$ & $74.24 \pm 10.31(56.0-100.7)$ & $62.12 \pm 9.97(45.7-91.4)$ \\
BMl $\left(\mathrm{kg} / \mathrm{m}^{2}\right)$ & $24.22 \pm 2.46(18.93-32.29)$ & $22.79 \pm 3.26(18.54-32.17)$ \\
FFM $(\mathrm{kg})$ & $60.75 \pm 8.36(48.0-88.9)$ & $48.20 \pm 6.41(36.6-63.5)$ \\
FFM (\%) & $81.84 \pm 6.10(71.3-94.1)$ & $77.72 \pm 6.75(54.9-91.5)$ \\
FM (kg) & $13.71 \pm 5.50(3.5-32.6)$ & $14.27 \pm 6.50(5.9-38.8)$ \\
FM (\%) & $18.16 \pm 6.10(7.8-32.4)$ & $22.28 \pm 6.75(8.5-54.1)$ \\
Training (h/w) & $8.50 \pm 4.60(1.0-30.0)$ & $9.91 .50 \pm 6.66(1.0-30.0)$
\end{tabular}

(12\% deviation), $\mathrm{H} \& \mathrm{~B}$ with $157.5 \pm 26.5 \mathrm{kcal} / \mathrm{d}$ (12\% deviation) and MÜL-FFM with $164.5 \pm 26.8 \mathrm{kcal} / \mathrm{d}$ (13\% deviation).

Figure 3 shows Bland-Altman plots for the six selected equations in men and women. The limits of agreement, based on the Bland-Altman plots, show the interval of two standard deviations of the measurement differences either side of the mean difference and were large in all six cases. For men, the De Lorenzo equation showed the smallest range with $615.2 \mathrm{kcal} / \mathrm{d}$. For women, the Cunningham equation showed the smallest range with $523.3 \mathrm{kcal} / \mathrm{d}$ (Table 2).

Table 3 shows the percentage of accuracy and the percentage of under- and overestimation of REE predictive equations. The De Lorenzo equation resulted in the highest percentage accurate predicted equations for men (72.2\%), the Cunningham equation for women (63.6\%). The Harris \& Benedict equation showed in both sexes less than 50\% accuracy. The WHO and the MÜL equations showed less than 50\% accuracy only in women.

\section{Linear Regression Analysis for REEm/FFM Ratio}

The relationship between REE and FFM was evaluated by linear regression. In the simple linear model, the FFM has a significant influence on the REE $(p<0.001)$ (Figure 4). The contribution of FFM to REE was calculated as $29.17 \pm 0.34 \mathrm{kcal} / \mathrm{kg}$ FFM for men and $30.42 \pm 0.52$ for women.

\section{Multiple Regression Analyses}

For multiple regression analyses, six participants were excluded due to missing body composition measurements (2 men, 1 woman), no indication of the sporting event (1 man), or no indication of the training hours per week ( 1 man, 1 woman), so the remaining 107 (75 men, 32 women) participants were included for the multiple regression analysis.

Body weight, age, sex, height, FFM, FM, training hours per week, phase angle, ambient temperature, and athletic specialization, assessed via their self-rated best event, (endurance: $n=31$, Power: $n=57$, mixed: $n=19$ ) were selected as predictor variables. The results of different models are given in Table 4. Body weight as the only predictor can explain $55.7 \%$ of the variance ( $p<0.001$, Model 1), while FFM as the only predictor can explain $63.0 \%$ of the variance $(p<0.001$, Model 2). All other predictors increase the explained variance only slightly. A hierarchical analysis of all measured predictors selects the best combination of variables, which is shown in Model 7. FFM $(p<0.001)$, FM $(p=0.007)$, temperature $(p=0.004)$ and gender $(p=0.045)$ are the only significant predictors of REE in this model, they explain $69.0 \%$ of the variance. By extending the model by anthropometric and sport-specific predictors, the explained variance increases only slightly. These variables have only small influence on REE and are therefore only partially suitable for predicting it.

One of the next steps could be to simplify the model by excluding all non-significant independent variables, in order to 


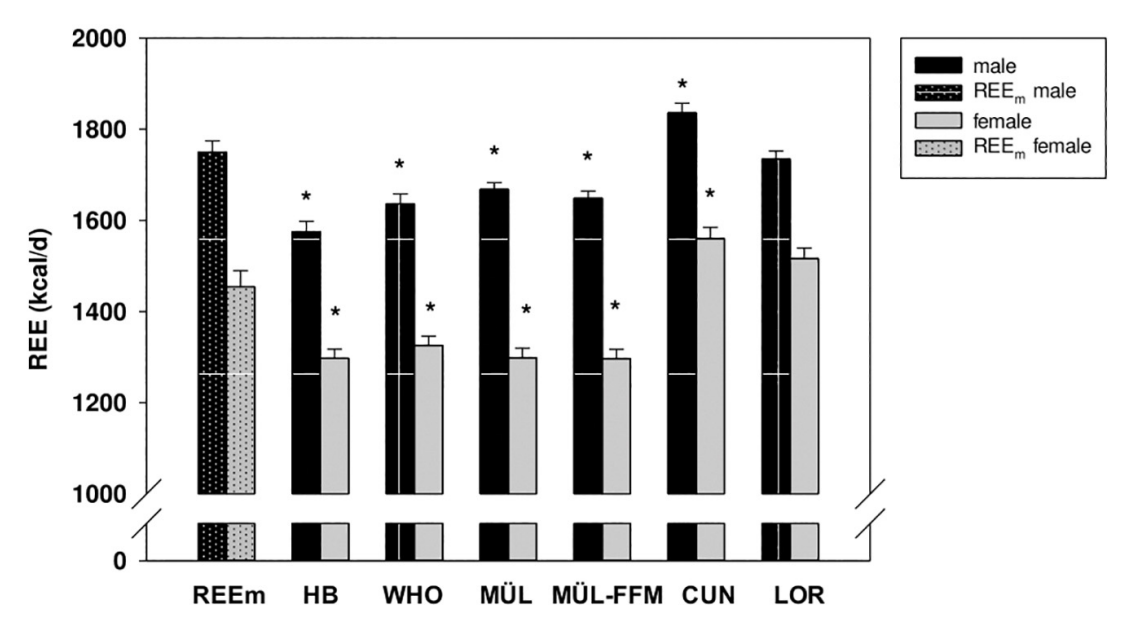

FIGURE 2 | Directly-measured resting energy expenditure (REE) (REEm) and predicted REE (REEp) using a variety of equations including Harris \& Benedict (H\&B), World Health Organization (WHO), Müller (MÜL), Müller-FFM (MÜL-FFM), Cunningham (CUN), and De Lorenzo (LOR) in males and female master athletes. ${ }^{*} p<0.005$ vs. REEm.

obtain a new predictive equation especially for master athletes to be tested and validated in independent cohort of master athletes.

$\mathrm{REE}=-202.088+18.577 \times \mathrm{FFM}(\mathrm{kg})+6.753 \times \mathrm{FM}$ $(\mathrm{kg})+23.910 \times$ temperature $\left({ }^{\circ} \mathrm{C}\right)+78.479 \times$ sex $(0=$ female, 1 = male $)$.

\section{DISCUSSION}

The main aims of this study were to assess the accuracy of existing predictive equations for REE applied to master athletes and to ascertain the primary determinants of REE in this group of athletes. The data presented herein show underestimation errors in most predicting equations by Harris \& Benedict (12\%), WHO/FAO (8\%) and Müller (5 and 7\% without and with FFM, respectively), whereas Cunningham's equation overestimated the actual REE by $4 \%$. Whilst predictions errors in the order of magnitude of $5 \%$ may seem acceptable in many other areas of research, they are of concern when it comes to providing dietary recommendations based on energy expenditure. Very clearly, overestimating the required caloric intake by such amounts will lead to obesity in the long run, and underestimation to starvation. The only equation that provided an accurate prediction on average was the one by De Lorenzo et al. (De Lorenzo et al., 1999), which is explained by the fact that it was specifically made for athletes. However, even though De Lorenzo's REE prediction may have been acceptable on average, it still over- or underestimated in $30 \%$ of master athletes.

The Harris \& Benedict equation, which is probably the most widely used approach in the clinical settings, resulted in about $50 \%$ of cases in accurate estimation of REE, in about $50 \%$ of cases in underestimation, but almost no overestimation in both men and women. The WHO and Müller equations (using body weight and FFM) resulted in about two thirds of men and almost $50 \%$ of women with accurate estimation of REE, about one third on men and about $50 \%$ on women with underestimation, but only in a few percent in overestimation. The Cunningham equation also resulted in about two thirds of both men and women with accurate estimation of REE, in less than $20 \%$ of cases in underestimation, but in more than $20 \%$ of cases a clear overestimation, specifically in women.

In general, our results of higher REE in master athletes are in accordance with the findings in other cross-sectional studies performed in young athletes (Ballor and Poehlman, 1992; Poehlman et al., 1992). The multiple regression analysis shows that this is mainly due to higher FFM in master athletes, compared with that of the general population. A previous study (ten Haaf and Weijs, 2014) pointed out that the Cunningham and De Lorenzo equations predicted REE in athletes more accurate than other commonly-used REE predictive equations (e.g., Harris \& Benedict, WHO, Schofield, Mifflin, Owen), with the De Lorenzo equation being slightly less accurate than the Cunningham equation. It should, however, be noted that these notions were based on data of recreational athletes of 18-35 years (ten Haaf and Weijs, 2014) and were not based on data obtained from highly trained master athletes as presented in this study.

Interestingly, the De Lorenzo's equation is the only predictive equation that was constructed based on a population of athletes. In their study, seven published REE equations were compared to assess the validity and reliability of REE estimations, based on a population of 51 young male athletes ( 22 water polo, 12 judo, and 17 karate) with a secondary aim of creating a specific equation for male athletes. In an attempt to improve the accuracy of the predictive equation, De Lorenzo et al. (De Lorenzo et al., 1999) incorporated body composition constituents, such as lean and fat mass obtained from DEXA scans. Contrary to expectations, FFM was not found to be the best predictor of REE, but rather a combination of height and body mass.

It is also of interest that the present study only found body weight, FFM, FM and sex as significant anthropometric 

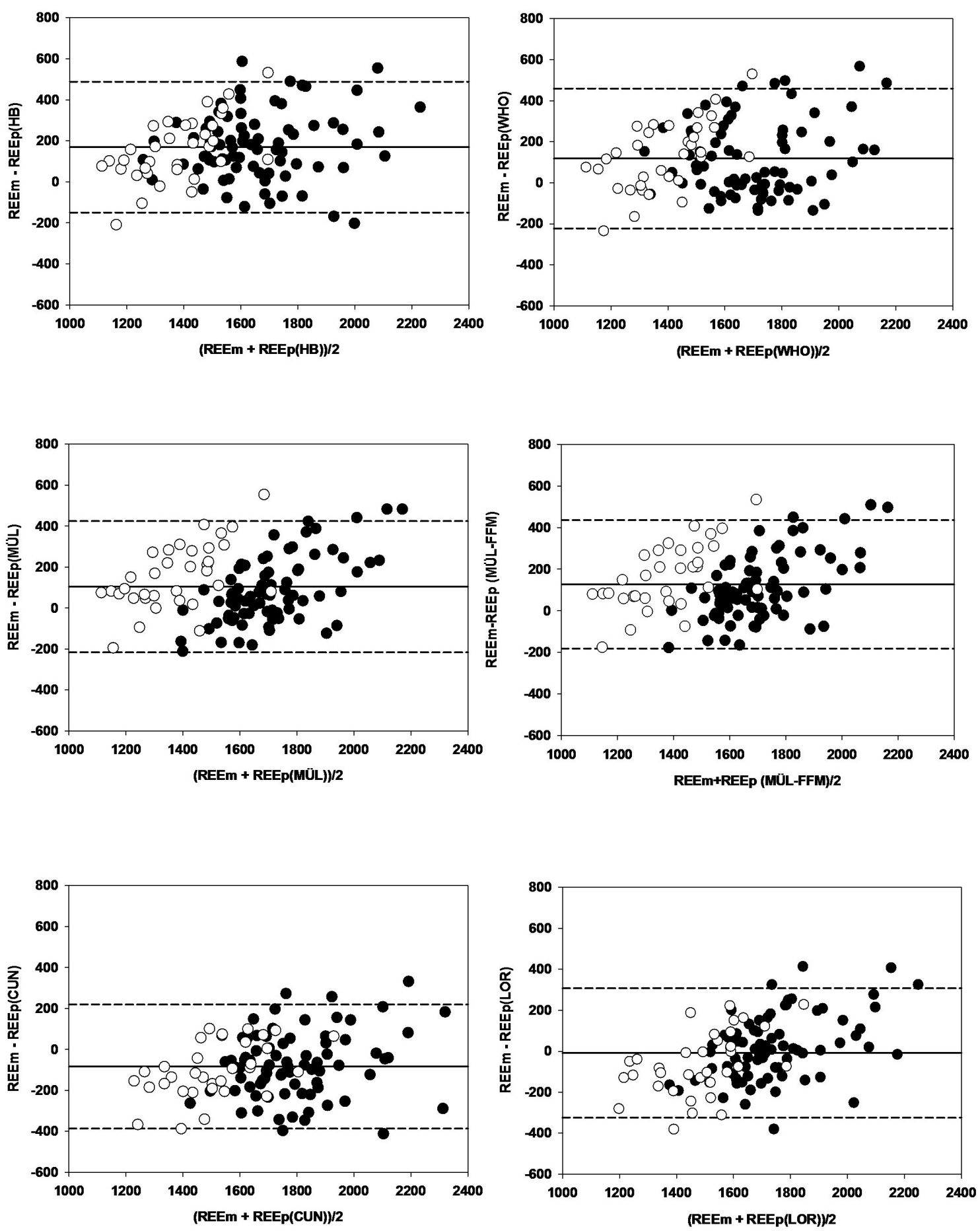

FIGURE 3 | Bland-Altman plots for six [Harris \& Benedict (HB), WHO (WHO), Müller (MÜL), MÜL -FFM (MÜL-FFM) Cunningham (CUN), De Lorenzo (LOR)] resting energy expenditure (REE) predictive equations (REEp). The solid lines represent the mean difference (BIAS) between predicted and measured REE (REEm). The upper and lower dashed lines represent $95 \%$ limits of agreement. o female $\bullet$ male.

predictors, but not age and height. This is noteworthy for two reasons. First, the absence of significant age effect suggests that master athletes maintain relatively high levels of basal metabolic rate, which also encompasses energy consumption as per repair and remodeling processes. Second, the finding of a significant contribution by FFM, FM and indicates that age effects by the previous predicting equation could be explained by age-related increases in body fat percentage. 
TABLE 2 | Limits of agreement.

\begin{tabular}{lcc}
\hline & \multicolumn{2}{c}{ Limits of agreement (range) (kcal/d) } \\
\cline { 2 - 3 } & \multicolumn{1}{c}{ Men } & Women \\
\hline Harris \& Benedict & -148.84 to $497.96(646.79)$ & -144.81 to $459.72(604.54)$ \\
WHO & -233.16 to $460.37(693.53)$ & -192.06 to $449.86(641.86)$ \\
Müller & -231.43 to $394.86(626.29)$ & -151.96 to $464.20(616.16)$ \\
Müller-FFM & -139.91 to $415.16(609.07)$ & -137.44 to $466.50(603.93)$ \\
Cunningham & -393.04 to $239.50(632.54)$ & -361.05 to $162.25(523.30)$ \\
De Lorenzo & -292.28 to $322.93(615.21)$ & -366.87 to $242.84(609.71)$ \\
\hline
\end{tabular}

Finally, we also checked the effect of ambient temperature. The average value during testing within the present study was $27.5^{\circ} \mathrm{C}$ which is higher than the above the temperature of $20-25^{\circ} \mathrm{C}$ that is recommended for the IC measurement by the manufacturer. Naturally, RMR assessments should normally be performed at a standard temperature, or at least controlled for it. Moreover, $5^{\circ} \mathrm{C}$ spread in this range seems per se quite wide, given the significant temperature effects observed in the present study. Unfortunately, the published literature neglects the temperature effect, and there is, to the best of our knowledge, only one study (Abreu-Vieira et al., 2015) that has investigated the effects of ambient temperature as influence factor on REE in mice.

Looking at the consequences that the elevated ambient temperature of the Málaga measurements may have had for the main study outcome, it is unfortunate that previous researchers had failed to analyze the effect of the ambient temperature information during their REE assessments. However, some simple calculations with the regression equation obtained from the present data suggest an excess REE by $23.91 \mathrm{kcal} /$ day can be attributed to each $1^{\circ} \mathrm{C}$-increase in ambient temperature (Table 4), and that therefore a deviation by $5 \times 23.91 \sim 120$ kcal could be cause by elevating ambient from $22.5^{\circ} \mathrm{C}$ to $27.5^{\circ} \mathrm{C}$. This amount is certainly a sizeable confounder, and it could potentially explain a good fraction of the excess REE observed in the present cohort, if not all of it. However, one also needs to consider that such model calculations involve extrapolation to ambient temperature levels below the range for which we have data, and that no information exists about temperature effects on REE in the $20-25^{\circ} \mathrm{C}$ range. Therefore, and given that the DeLorenzo equation predicts higher REE in athletes than non-athletes, we still hold it likely that athletic participation is also associated with increased REE levels at old age.

The present study shows that the De Lorenzo equation, by taking height and body weight into account, is remarkably similar to the Cunningham equation that takes the athlete's FFM into account. These results are in accordance with the result of our multiple regression analysis that body weight as well as FFM are both significant predictors of REE in master athletes. One explanation for this equality in predictiveness could be the lower fat mass of the master athletes $(18.2 \pm 6.1 \%$ in men and $22.3 \pm 6.8 \%$ in women) in comparison to the general elderly population (Deurenberg et al., 1989; Ofenheimer et al., 2020).

TABLE 3 | Accuracy of predictive equations.

\begin{tabular}{|c|c|c|c|c|c|c|}
\hline & \multicolumn{2}{|c|}{ Underestimation (\%) } & \multicolumn{2}{|c|}{ Accurate estimation $( \pm 10 \%)$} & \multicolumn{2}{|c|}{ Overestimation (\%) } \\
\hline & Men & Women & Men & Women & Men & Women \\
\hline WHO & 36.7 & 52.9 & 63.3 & 41.2 & 0 & 5.9 \\
\hline Müller & 27.9 & 50.0 & 65.8 & 47.1 & 6.3 & 2.9 \\
\hline Müller-FFM & 32.5 & 51.5 & 66.2 & 45.5 & 1.3 & 3.0 \\
\hline
\end{tabular}

Bolded values denotes that, this is the most accurate estimation in men and in women.
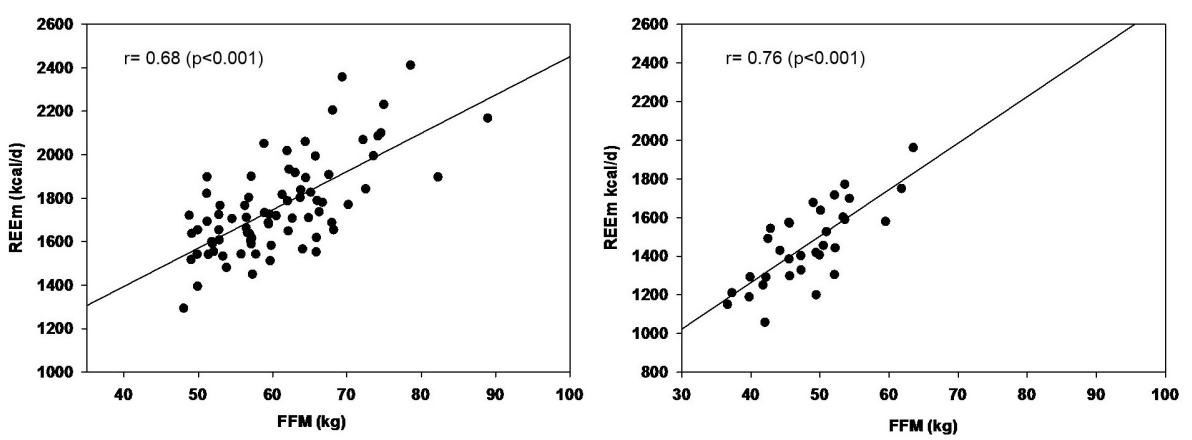

FIGURE 4 | Relationship between the measured resting energy expenditure (REEm) and fat free mass (FFM) of master athletes. On the left: men ( $r=0.69$, $p<0.001)$, on the right: women $(r=0.76, p<0.001)$. 
TABLE 4 | Multiple regression model to determine independent predictors of resting energy expenditure (REE) (kcal/d).

\begin{tabular}{|c|c|c|c|}
\hline $\begin{array}{l}\text { Equation } \\
\text { number }\end{array}$ & Tested variables & Equation & $\begin{array}{l}\text { Explained } \\
\text { variance }\left(R^{2}\right)\end{array}$ \\
\hline Model 1 & Body weight & REE $=505.233+16.372 \times$ body weight $(\mathrm{kg})$ & $55.7 \%$ \\
\hline Model 2 & FFM & $\mathrm{REE}=494.873+20.623 \times \mathrm{FFM}(\mathrm{kg})$ & $63.1 \%$ \\
\hline Model 3 & FFM, FM & $\mathrm{REE}=439.574+20.462 \times \mathrm{FFM}(\mathrm{kg})+4.645 \times \mathrm{FM}(\mathrm{kg})$ & $64.2 \%$ \\
\hline Model 4 & FFM, FM, gender, age, height & $\begin{array}{l}\text { REE }=431.859+17.6 \times \text { FFM }(\mathrm{kg})+5.462 \times \mathrm{FM}(\mathrm{kg})+73.951 \times \text { sex }(\text { female }=0 \\
\text { male }=1)-0.602 \times \text { age }(\text { years })+0.821 \times \text { height }(\mathrm{cm})\end{array}$ & $65.3 \%$ \\
\hline Model 5 & $\begin{array}{l}\text { FFM, FM, gender, age, height, } \\
\text { temperature }\end{array}$ & $\begin{array}{l}\mathrm{REE}=-99.565+19.664 \times \mathrm{FFM}(\mathrm{kg})+5.761 \times \mathrm{FM}(\mathrm{kg})+62.716 \times \text { sex }(\text { female }=0, \text { male }=1) \\
-0.308 \times \text { age }(\text { years })-0.610 \times \text { height }(\mathrm{cm})+23.531 \times \text { temperature }\left({ }^{\circ} \mathrm{C}\right)\end{array}$ & $68.0 \%$ \\
\hline Model 6 & $\begin{array}{l}\text { FFM, FM, gender, age, height, } \\
\text { temperature, training hours, } \\
\text { phase angle, kind of sports* }\end{array}$ & $\begin{array}{l}\mathrm{REE}=-131.956+18.823 \times \mathrm{FFM}(\mathrm{kg})+6.994 \times \mathrm{FM}(\mathrm{kg})+77.484 \times \text { sex }(\text { female }=0 \\
\text { male }=1)+0 \times \text { age }(\text { years })-0.567 \times \text { height }(\mathrm{cm})+22.550 \times \text { temperature } \\
\left({ }^{\circ} \mathrm{C}\right)+0.007 \times \text { training hours }(\text { hours })+7.104 \times \text { phase angle }\left({ }^{\circ}\right)+24.245 \times \text { endurance }- \\
9.736 \times \text { mixed } \\
\text { *based on strength as reference }\end{array}$ & $69.3 \%$ \\
\hline Model 7 & FFM, FM, temperature, gender & $\begin{array}{l}\mathrm{REE}=-202.088+18.577 \times \mathrm{FFM}(\mathrm{kg})+6.753 \times \mathrm{FM}(\mathrm{kg})+23.910 \times \text { temperature } \\
\left({ }^{\circ} \mathrm{C}\right)+78.479 \times \operatorname{sex}(\text { female }=0, \text { male }=1)\end{array}$ & $69.0 \%$ \\
\hline
\end{tabular}

A lower fat mass would effectively mean that FFM makes up a larger proportion of the total body mass in master athletes than in comparable non-exercising populations. This is supported by the comparison of the two Müller equations, which show similar results despite different predicators. While MÜL only uses the total body mass, MÜL-FFM additionally includes FFM. Though important determinants, body weight and FFM are not the sole predictors of REE; despite the inclusion of the FFM, for instance, the Müller equation showed less accuracy in predicting REE compared with the Cunningham equation. Since Müller et al. (2004) developed their equation primarily for the German, predominantly Caucasian population, the differences are potentially due to ethnic differences, which would require further investigation. However, it is interesting that the BlandAltman Plots of the Müller equation show two separate clusters for men and women, which were not observed within the other equations.

A bias ranging from $-587 \mathrm{kcal} / \mathrm{d}$ to $0 \mathrm{kcal} / \mathrm{d}$ was observed when the REE was predicted in master athletes. The question of what is an acceptable bias, needs to be evaluated from a practical perspective and depends on the individual training situation. However, the primary goal should be to avoid an energy deficiency in master athletes relative to what can be achieved through individual dietary advice.

The championship setting offered a unique opportunity to measure REE in many competitive master athletes over a short period with a modern, non-invasive technique. This was met by high interest and demand by master athletes participating in the Championship $(n=113)$. Unfortunately, this strength was also a limitation regarding the environmental conditions. There was only one test room for all measurements available in the stadium, although an REE-measurement requires a calm atmosphere. Ambient temperature $\left(25-31^{\circ} \mathrm{C}\right)$ and humidity were relatively high $(43-70 \%)$, which made calm breathing under the canopy difficult for some of the athletes. Unfortunately, day-today variations of temperature and humidity were unavoidable and reduced the required standardization. Independent of the environmental conditions, the age range (34-84 years) was large within the participants and the menopausal status was not considered in the evaluation (Van Pelt et al., 1997). In terms of the multiple linear regression, some variables affected others (e.g., FFM affecting body weight), which can lead to multicollinearity. On the other hand, this is hard to avoid when analyzing anthropometric data. Despite all being master athletes, the participants were heterogeneous in terms of the different sports disciplines and the associated FFM. For further investigations, it may be useful to stratify more by age, height, sex and sports to define the influence of FFM on REE. In this context, it would also be desirable to measure the FFM with devices that are specifically validated for athletes. In order to normalize the REE data for organ and tissue masses according to Bosy-Westphal et al. (2013) and Muller et al. (2018) MRI data of master athletes would be of great interest for future studies.

In summary, it is important to be careful when using REE equations in athletic individuals, given the body compositional differences between athletic and non-exercising populations. Typically, REE will be underestimated with REE equations that do not account for FFM and are not specifically developed for an athletic population. For the special collection of older competitive athletes, the present study provides an initial overview of their energy requirements. Further investigations under more standardized study conditions (e.g., controlled environmental conditions, standardized diet some days before the measurement) would be desirable in order to predict REE of master athletes more precisely than previously possible.

\section{DATA AVAILABILITY STATEMENT}

The original contributions presented in the study are included in the article/supplementary material, further inquiries can be directed to the corresponding author/s.

\section{ETHICS STATEMENT}

The studies involving human participants were reviewed and approved by Ärtzekammer Nordrhein, Düsseldorf, Germany. 
The patients/participants provided their written informed consent to participate in this study.

\section{AUTHOR CONTRIBUTIONS}

PF-M, NR, WS, SM, EM, and FH carried out the experiment. $\mathrm{PF}-\mathrm{M}$ and $\mathrm{SH}$ wrote the manuscript with support from $\mathrm{MB}$ and JR. PF-M and SH performed the analytical calculations. HT, PC, JA, and JR helped supervise the project. UM and WS managed the data. PF-M and MB conceived the original idea. All authors discussed the results and contributed to the final manuscript.

\section{REFERENCES}

Abreu-Vieira, G., Xiao, C., Gavrilova, O., and Reitman, M. L. (2015). Integration of body temperature into the analysis of energy expenditure in the mouse. Mol. Metab. 4, 461-470. doi: 10.1016/j.molmet.2015.03.001

Amaro-Gahete, F. J., Sanchez-Delgado, G., Alcantara, J. M. A., Martinez-Tellez, B., Muñoz-Hernandez, V., Merchan-Ramirez, E., et al. (2019). Congruent validity of resting energy expenditure predictive equations in young adults. Nutrients 11:223. doi: 10.3390/nu11020223

Ballor, D. L., and Poehlman, E. T. (1992). Resting metabolic rate and coronaryheart-disease risk factors in aerobically and resistance-trained women. Am. J. Clin. Nutr. 56, 968-974. doi: 10.1093/ajcn/56.6.968

Bosy-Westphal, A., Braun, W., Schautz, B., and Muller, M. J. (2013). Issues in characterizing resting energy expenditure in obesity and after weight loss. Front. Physiol. 4:47. doi: 10.3389/fphys.2013.00047

Campbell, W. W., Crim, M. C., Young, V. R., and Evans, W. J. (1994). Increased energy requirements and changes in body composition with resistance training in older adults. Am. J. Clin. Nutr. 60, 167-175. doi: 10.1093/ajcn/60.2.167

Cherian, K. S., Shahkar, F., Sainoji, A., Balakrishna, N., and Yagnambhatt, V. R. (2018). Resting metabolic rate of Indian junior soccer players: testing agreement between measured versus selected predictive equations. Am. J. Hum. Biol. 30:e23066. doi: 10.1002/ajhb.23066

Cunningham, J. J. (1980). A reanalysis of the factors influencing basal metabolic rate in normal adults. Am J. Clin. Nutr. 33, 2372-2374. doi: 10.1093/ajcn/33.11. 2372

De Lorenzo, A., Bertini, I., and Candeloro, N. (1999). A new predictive equation to calculate resting metabolic rate in athletes. J. Sports Med. Phys. Fitness. 39, 213-219.

Delsoglio, M., Achamrah, N., Berger, M. M., and Pichard, C. (2019). Indirect calorimetry in clinical practice. J. Clin. Med. 8:1387. doi: 10.3390/jcm809 1387

Desbrow, B., Burd, N. A., Tarnopolsky, M., Moore, D. R., and Elliott-Sale, K. J. (2019). Nutrition for special populations: young, female, and masters athletes. Int. J. Sport Nutr. Exerc. Metab. 29, 220-227. doi: 10.1123/ijsnem.2018-0269

Deurenberg, P., van der Kooy, K., Hulshof, T., and Evers, P. (1989). Body mass index as a measure of body fatness in the elderly. Eur. J. Clin. Nutr. 43, 231-236.

Ferrannini, E. (1988). The theoretical bases of indirect calorimetry: a review. Metabolism 37, 287-301. doi: 10.1016/0026-0495(88)90110-2

Frączek, B., Grzelak, A., and Klimek, A. T. (2019). Analysis of daily energy expenditure of elite athletes in relation to their sport, the measurement method and energy requirement norms. J. Hum. Kinet. 70, 81-92. doi: 10.2478/hukin2019-0049

Harris, J. A., and Benedict, F. G. (1918). A biometric study of human basal metabolism. Proc. Natl. Acad. Sci. U.S.A. 4, 370-373. doi: 10.1073/pnas.4.12.370

Haugen, H. A., Chan, L. N., and Li, F. (2007). Indirect calorimetry: a practical guide for clinicians. Nutr. Clin. Pract. 22, 377-388. doi: 10.1177/ 0115426507022004377

Jagim, A. R., Camic, C. L., Kisiolek, J., Luedke, J., Erickson, J., Jones, M. T., et al. (2018). Accuracy of resting metabolic rate prediction equations in athletes. J. Strength Cond. Res. 32, 1875-1881. doi: 10.1519/jsc.0000000000002111

Johnstone, A. M., Murison, S. D., Duncan, J. S., Rance, K. A., and Speakman, J. R. (2005). Factors influencing variation in basal metabolic rate include fat-free

\section{FUNDING}

This research was funded by the German Aerospace Center.

\section{ACKNOWLEDGMENTS}

The authors are grateful to Alvaro del Pozo and Daniel Pérez Martínez of the Royal Athletic Spanish Federation, to the World Masters Athletics (WMA), Irmtrud Schrage, lab technician, and naturally to all study participants.

mass, fat mass, age, and circulating thyroxine but not sex, circulating leptin, or triiodothyronine. Am. J. Clin. Nutr. 82, 941-948. doi: 10.1093/ajcn/82.5.941

Müller, M. J., Bosy-Westphal, A., Klaus, S., Kreymann, G., Lührmann, P. M., Neuhäuser-Berthold, M., et al. (2004). World Health Organization equations have shortcomings for predicting resting energy expenditure in persons from a modern, affluent population: generation of a new reference standard from a retrospective analysis of a German database of resting energy expenditure. Am. J. Clin. Nutr. 80, 1379-1390. doi: 10.1093/ajcn/80.5.1379

Muller, M. J., Geisler, C., Hubers, M., Pourhassan, M., Braun, W., and BosyWestphal, A. (2018). Normalizing resting energy expenditure across the life course in humans: challenges and hopes. Eur. J. Clin. Nutr. 72, 628-637. doi: 10.1038/s41430-018-0151-9

Ofenheimer, A., Breyer-Kohansal, R., Hartl, S., Burghuber, O. C., Krach, F., Schrott, A., et al. (2020). Reference values of body composition parameters and visceral adipose tissue (VAT) by DXA in adults aged 18-81 years-results from the LEAD cohort. Eur. J. Clin. Nutr. 74, 1181-1191. doi: 10.1038/s41430-020-0596-5

Pinheiro Volp, A. C., Esteves de Oliveira, F. C., Duarte Moreira Alves, R., Esteves, E. A., and Bressan, J. (2011). Energy expenditure: components and evaluation methods. Nutr. Hosp. 26, 430-440. doi: 10.1590/s0212-16112011000300002

Poehlman, E. T., Gardner, A. W., Ades, P. A., Katzman-Rooks, S. M., Montgomery, S. M., Atlas, O. K., et al. (1992). Resting energy metabolism and cardiovascular disease risk in resistance-trained and aerobically trained males. Metabolism 41, 1351-1360. doi: 10.1016/0026-0495(92)90107-1

Poehlman, E. T., and Horton, E. S. (1990). Regulation of energy expenditure in aging humans. Annu. Rev. Nutr. 10, 255-275. doi: 10.1146/annurev.nu.10. 070190.001351

Poehlman, E. T., Melby, C. L., and Badylak, S. F. (1991a). Relation of age and physical exercise status on metabolic rate in younger and older healthy men. J. Gerontol. 46, B54-B58. doi: 10.1093/geronj/46.2.b54

Poehlman, E. T., Melby, C. L., and Goran, M. I. (1991b). The impact of exercise and diet restriction on daily energy expenditure. Sports Med. 11, 78-101. doi: 10.2165/00007256-199111020-00002

Poehlman, E. T., Viers, H. F., and Detzer, M. (1991c). Influence of physical activity and dietary restraint on resting energy expenditure in young nonobese females. Can. J. Physiol. Pharmacol. 69, 320-326. doi: 10.1139/y91-049

Rodriguez, N. R., DiMarco, N. M., and Langley, S. (2009). Position of the american dietetic association, dietitians of canada, and the american college of sports medicine: nutrition and athletic performance. J. Am. Diet. Assoc. 109, 509-527. doi: 10.1016/j.jada.2009.01.005

Ryan, A. S., Nicklas, B. J., and Elahi, D. (1996). A cross-sectional study on body composition and energy expenditure in women athletes during aging. Am. J Physiol. 271, E916-E921. doi: 10.1152/ajpendo.1996.271.5.E916

Schofield, K. L., Thorpe, H., and Sims, S. T. (2019). Resting metabolic rate prediction equations and the validity to assess energy deficiency in the athlete population. Exp. Physiol. 104, 469-475. doi: 10.1113/ep087512

Stavres, J., Zeigler, M. P., and Bayles, M. (2019). Six weeks of moderate functional resistance training increases basal metabolic rate in sedentary adult women. Int. J. Exerc. Sci. 11, 32-41.

Sullo, A., Cardinale, P., Brizzi, G., Fabbri, B., and Maffulli, N. (2004). Resting metabolic rate and post-prandial thermogenesis by level of aerobic power in older athletes. Clin. Exp. Pharmacol. Physiol. 31, 202-206. doi: 10.1111/j.14401681.2004.03979.x 
Tanaka, H., Tarumi, T., and Rittweger, J. (2019). Aging and physiological lessons from master athletes. Compr. Physiol. 10, 261-296. doi: 10.1002/cphy.c180041

ten Haaf, T., and Weijs, P. J. (2014). Resting energy expenditure prediction in recreational athletes of 18-35 years: confirmation of Cunningham equation and an improved weight-based alternative. PLoS One 9:e108460. doi: 10.1371/ journal.pone. 0108460

Thompson, J., and Manore, M. M. (1996). Predicted and measured resting metabolic rate of male and female endurance athletes. J. Am. Diet. Assoc. 96, 30-34. doi: 10.1016/s0002-8223(96)00010-7

Tzankoff, S. P., and Norris, A. H. (1977). Effect of muscle mass decrease on age-related BMR changes. J. Appl. Physiol. Respir. Environ. Exerc. Physiol. 43, 1001-1006. doi: 10.1152/jappl.1977.43.6.1001

Van Pelt, R. E., Jones, P. P., Davy, K. P., Desouza, C. A., Tanaka, H., Davy, B. M., et al. (1997). Regular exercise and the age-related decline in resting metabolic rate in women. J. Clin. Endocrinol. Metab. 82, 3208-3212.

Vander Weg, M. W., Watson, J. M., Klesges, R. C., Eck Clemens, L. H., Slawson, D. L., and McClanahan, B. S. (2004). Development and cross-validation of a prediction equation for estimating resting energy expenditure in healthy African-American and European-American women. Eur. J. Clin. Nutr. 58, 474-480. doi: 10.1038/sj.ejcn.1601833
Vaughan, L., Zurlo, F., and Ravussin, E. (1991). Aging and energy expenditure. Am. J. Clin. Nutr. 53, 821-825. doi: 10.1093/ajcn/53.4.821

Weir, J. B. (1949). New methods for calculating metabolic rate with special reference to protein metabolism. J. Physiol. 109, 1-9.

Welle, S., and Nair, K. S. (1990). Relationship of resting metabolic rate to body composition and protein turnover. Am. J. Physiol. 258, E990-E998. doi: 10. 1152/ajpendo.1990.258.6.E990

WHO (1985). Energy and Protein Requirements. Geneva: WHO.

Conflict of Interest: The authors declare that the research was conducted in the absence of any commercial or financial relationships that could be construed as a potential conflict of interest.

Copyright (c) 2021 Frings-Meuthen, Henkel, Boschmann, Chilibeck, Alvero Cruz, Hoffmann, Möstl, Mittag, Mulder, Rittweger, Sies, Tanaka and Rittweger. This is an open-access article distributed under the terms of the Creative Commons Attribution License (CC BY). The use, distribution or reproduction in other forums is permitted, provided the original author(s) and the copyright owner(s) are credited and that the original publication in this journal is cited, in accordance with accepted academic practice. No use, distribution or reproduction is permitted which does not comply with these terms. 